\title{
Societal Perception of Communication Strategies among Married Couples in Nsukka, South-Eastern, Nigeria
}

\author{
Christian Iyiani, Christopher Ngwu \\ Department of Social Work, University of Nigeria, Nsukka, Nigeria \\ Email: chrysiyiani@yahoo.ca,ngwuchris@yahoo.com
}

Received July $18^{\text {th }}, 2012$; revised August $16^{\text {th }}, 2012$; accepted August $27^{\text {th }}, 2012$

\begin{abstract}
When communication between couples becomes strained or even non-existent, the entire foundation of the relationship is affected. The purpose of this study therefore was to examine communication strategies that will improve couple's relationships. Data were gathered from 197 couples of Igbo ethnic group using a 20-item scale measuring societal perception of married couples. Results showed that about half of the respondents $(51.1 \%)$ were able to identify strategies couples can take to reduce misunderstanding in marriage relationship. The study also revealed that $53.2 \%$ of the respondents were of the opinion that culture has an influence on effective communication among couples. A major implication of the findings is the need to focus mainly on improving marital relationship through application of effective communication strategies by couples.
\end{abstract}

Keywords: Perception; Communication Strategies; Married Couples; Effective Communication

\section{Introduction}

Communication as a concept has its origin from a Latin word "communicare" which means to share or establish commonness. Communication is a tool for inter-personal relationship which involves sharing of ideas and information towards reaching an understandable agreement or view (Diringer, 1997). Communication can be described as a social process that uses signs, symbols, languages and other such means to bring about inter-exchange of thought and meaning between and among individuals and groups for better understanding and relationships (Ogili, 2005). Many people usually think of communication primarily in oral or written form but the fact remains that communication is far much more than that, for instance, a gentle touch can enable one communicate a message louder and clearer.

Most people think of communication as merely speaking, yet communication is multifaceted and involves listening skills and non-verbal communications as well (Linda, 2010). According to P.S. Perkins (2008), most people are unaware that when they are speaking, it is just a replay of something they have been taught to think as right or wrong, healthy or unhealthy. However, many people do not know that it is important to have the ability to listen to what another person is saying. Linda (2010) corroborated this when she indicated that listening to and focusing on what another person says can eliminate ambiguities and avoid miscommunication of potential disagreements.

According to Deborah (2002) lack of communication among couples adversely affects the whole personality of the couples including their personal, professional and social life. When couples are unable to communicate, a huge gap opens and stops the flow of that life giving water that was supposed to nourish and make it grow (Schramm, 1954). It causes everything around the marriage to suffer and tension deepens. Lack of communication in marriage can make couples feel lonely, isolated and in such a situation, such couples tend to withdraw from social activities and are emotionally vulnerable. In recent times, lack of communication among couples has contributed immensely in the divorce rate in countries like USA, Europe, South-Africa and Nigeria (Harold, 2002). Many couples are unable to reach a level of understanding and therefore issues are left unresolved and tension deepens, leading to lack of understanding and respect. Ultimately, lack of communication may lead couples to dissolve the relationship for lack of knowing how to fix the problems.

Effective communication is the glue that holds the relationship among married couples together. An effective communicator should consider the culture of the recipient and adapt to it. Men and women don't communicate the same way (Debora, 1985). Studies have shown that there are differences in brain patterns between men and women which affect their ability to communicate and interpret information with each other. The culture in question is not tradition but patterns and approaches for which every sex understands and communicates. According to clinical psychologist Dr. Larry Nadig, communication is successful between two people when the message is correctly sent and received with no misunderstanding. Communication is a complex process and it is sometimes difficult to achieve effective communication because many things can interfere with the process of communication and causes distortions in the message (Mbazu, 2009). Deborah (2002) maintained that marriage with good communication does not only seem to last longer, but that the couples involved in such relationship are happier than people stuck in unhealthy and non-communicating relationship. This implies that effective communication has good effects on couples who make use of it properly.

For communication to be effective, it must be a two way process in which the receiver of the original message responds or reacts to the message. In the same vein, Appley in Emenike (1997) argued that for effective communication to take place, the mastery of basic communication processes must involve the following steps: 
$>$ Clarifying the idea of problem.

$>$ Participate in developing a solution to the problem.

$>$ Motivating others to take action agreed upon.

$>$ Measuring the effectiveness of communication.

\section{Communication Strategies among Married Couples}

A marriage can stand or fall on the basis of how well the couples can communicate with each other. Committed couples care about and consistently work at the quality of their relationship (Eboni \& Deborah, 2010). Couples who have healthy marriages, love and respect each other and use many factors that are important in the success of a marriage. The ability to communicate with each other has been adjudged the best in marriage relationship. Despite the difficulties couples may experience, those who can communicate clearly with each other have a much better chance of overcoming problems and staying together.

Effective communication can keep marriages together even in the most difficult times. One can conclude that the most important element of a successful marriage should be the couples' ability to communicate with each other. Gottman and Levenson (1988) have offered specific couple communication patterns that contributed immensely to satisfactory couple relationship, with specific focus on the close personal relationship of marriage. According to Joyce (1982), there are many strategies used to develop healthier communication patterns in marriage. Some of the strategies include:

Firstly, finding time to talk-According to Eboni and Deborah (2010), taking time to listen keeps the lines of communication open and improves marriage relationship. Couples need to take time to talk about their reactions and how they are perceived so they can develop a better understanding of each other's subtleties and nuances. Without sufficient time together, it is not possible to learn to communicate well with each other. Because time is difficult to come by, one should make a deliberate effort to make time for each other. The best way to do this is to set aside a regular time to talk about what is going on in ones lives at a moment and devote all attention while at it (Harold, 2001).

Secondly, there should be clarity in any couple's relationship to avoid confusion and misinterpretation. According to Linda, (2010) couples need to consider the volume of their voice, their facial expression, body language and choice of words. For example, a couple may be saying something perfectly benign, but if he/she is shouting and frowning, it may be taken as an attack. The clearer the couple is, the more chances he will be properly understood. Many couples assume that their partners know their needs, feelings and opinions even though they have never actually been verbalized. This is wrong because the partners need to state their thoughts as clearly, honestly and positively as possible.

Thirdly, another step couple can take to avoid misunderstanding in marriage relationship includes the listener's focus. As a listener, there are precautions couple can take to ensure more effective communication. Couples are more likely to get the full measure of the speaker's intent when their focus is completely on the other person without distractions. An effective listener asks questions and reserves judgment until he fully understands what the other person is trying to convey. Eboni and Deborah (2010) argued that a good listener does more than just hear words; he interprets emotions, behaviors and responds appropriately.

Fourthly, to avoid being passive is another good strategy in marriage relationship. This means that when any of the partners has a complaint or want to discuss something with the other, he/she should not cross arms or turn to walk out on or from each other. Robin Fields (2001) suggests that it is better to take a deep breath and calm down, no matter how uncomfortable a spouse makes one or the subject of discussion or if any conflict tends to make one nervous. Linda (2010) Opines that both speakers and listeners must pay attention to body language signals to achieve effective communication. Listeners should watch for inconsistencies in the words being spoken and the body language displayed. For example, if a partner says she is happy with a decision but she is clenching her fists and pacing, she may not be telling the truth.

There are many communication strategies among married couples which could not be exhausted in this article. Nevertheless, one can pin down the strategies into two major types of communication-verbal and non-verbal communication. Most part of individual communication or interactions are hidden in the non-verbal communication strategy. So couples should observe and embark on understanding both the non-verbal and verbal interactions between each other.

\section{Methods}

A survey was conducted to examine the societal perception of communication strategies among married couples in Nsukka, South Eastern, Nigeria. A cross-sectional design was employed in the study where societal perception of communication strategies among married couples was measured based on a-20 variable responses. The chi-square $\left(\mathrm{X}^{2}\right)$ test of association was used to test for the association of variables in the study. The sample for this study consisted of 197 married couples $(53 \%$ females and $47 \%$ males) selected through cluster and simple random sampling methods from the three autonomous communities that make up Nsukka Town. Namely Nkpunanor, Nru and Ihe/Owerre.

Cluster sampling was applied to select the autonomous communities within the town and simple random sampling was applied to select respondents from the villages. Analysis was therefore based on the responses of 197 respondents. All the respondents were married couples and the majority of them are from Nsukka senatorial zone of Enugu State.

The assistance and co-operation of the three traditional rulers in each of the autonomous communities was sought and obtained in order to mobilize the participants in their domain. However, assurances on the confidentiality of the data generated in the study were made to participants who were skeptical about the results and consequences of their participation in the study.

A structured questionnaire on knowledge of effective communication and strategies that can improve marital relationship among couples was used for the collection of data. The first part of the questionnaire solicited personal descriptive information from the respondents. The purpose of the questionnaire was to assess the societal perception of communication strategies among married couples in Nsukka urban area.

The questionnaires were administered only to the married couples (both old and young) especially those who showed readiness to participate in the study, only 197 questionnaires 
out of 200 were found to be duly completed and these were subjected to analysis. The data collected was processed and analyzed using statistical package for the social sciences (SPSS).

A descriptive of statistical packages for social sciences was used. The first part of analysis was done using socio-demographic characteristics of respondents such as sex, age, education and marital status. The second part of the analysis was done using frequency, simple percentages and chi-square to test the variables used in the study.

Results: Socio-demographic characteristics of respondents.

The study reveals that most of the respondents fall within the age bracket of $30-35$ years in this category, $20 \%$ and $13 \%$ were males and females respectively. The findings show that out of the younger respondents (18 - 35 years) $44.5 \%$ were males and 35.5\% were females. In Table 1 above, the findings of the educational qualifications of the respondents show that most of the respondents (39.6\%) fall within the range of those who posses diploma degree certificates. Out of this number, about $24 \%$ and $16 \%$ of the respondents were males and females respectively. For those who completed their secondary education, $16 \%$ and $13 \%$ were males and females respectively.

The study also revealed that $15 \%$ of the male and $9 \%$ of the female respondents were civil servants. $42.1 \%$ of the respondents were engaged in different occupational activities where about $22 \%$ of them were males and $20 \%$ (females).

The above Table 2 shows the sex of respondents and their level of awareness of communication strategies. The study investigated the respondents' perception of communication strategies among couples in Nsukka Town of Enugu State. The

Table 1.

Percentage distribution of respondents by background information.

\begin{tabular}{|c|c|c|c|}
\hline \multicolumn{4}{|c|}{ Age of respondents and sex crosstab } \\
\hline \multicolumn{4}{|c|}{ Sex } \\
\hline Age range & Male & Female & Total \\
\hline $18-23$ & $5(2.5 \%)$ & $13(6.6 \%)$ & $18(9.1 \%)$ \\
\hline $24-29$ & $23(11.7 \%)$ & $31(15.7 \%)$ & $54(27.4 \%)$ \\
\hline $30-35$ & $40(20.3 \%)$ & $26(13.2 \%)$ & $66(33.5 \%)$ \\
\hline 36 and above & $37(18.8 \%)$ & $22(11.2 \%)$ & $59(29.9 \%)$ \\
\hline Total & $105(53.3 \%)$ & $92(46.7 \%)$ & $197(100 \%$ \\
\hline $\begin{array}{l}\text { Educational } \\
\text { attainment }\end{array}$ & Male & Female & Total \\
\hline $\begin{array}{l}\text { Primary } \\
\text { completed }\end{array}$ & $8(4.1 \%)$ & $12(6.1 \%)$ & $20(10.2 \%)$ \\
\hline $\begin{array}{l}\text { Secondary } \\
\text { completed }\end{array}$ & $32(16.2 \%)$ & $26(13.2 \%)$ & $58(29.4 \%)$ \\
\hline $\begin{array}{l}\text { Secondary } \\
\text { uncompleted }\end{array}$ & $18(9.1 \%)$ & $23(11.7 \%)$ & $41(20.8 \%)$ \\
\hline Diploma/degree & 47 (23.9\%) & $31(15.7 \%)$ & $78(39.6 \%)$ \\
\hline Total & $105(53.3 \%)$ & $92(46.7 \%)$ & $197(100 \%)$ \\
\hline $\begin{array}{l}\text { Occupation of } \\
\text { respondents }\end{array}$ & Male & Female & Total \\
\hline Civil servant & $30(15.2 \%)$ & $17(8.6 \%)$ & $47(23 . \%)$ \\
\hline Trader & $21(10.7 \%)$ & $26(13.2 \%)$ & $47(23.9 \%)$ \\
\hline Students & $11(5.6 \%)$ & $9(4.6 \%)$ & $20(10.2 \%)$ \\
\hline Others & $43(21.8 \%)$ & $40(20.3 \%)$ & $197(100.00 \%)$ \\
\hline Total & $105(53.3 \%)$ & $92(46.7 \%)$ & $197(100.00 \%)$ \\
\hline
\end{tabular}

findings revealed that $78.2 \%$ of the respondents were aware of the communication strategies among couples. In disaggregating the data by sex, the study showed that about $47 \%$ of the male respondents were aware of the communication strategies among couples as against their female counter parts $(31.5 \%)$. The high response among the males in this study could be attributed to their high educational attainment and patriarchal system in Nsukka town.

Gender has always been regarded as an important determinant of reactions, opinions and attitudes towards the knowledge or understanding of certain issues in the society. The Table 3 above sought to know the difference between the male and female understanding of effective communication. The results, however, showed that $26 \%$ of male and $15 \%$ of female respondents were able to explain effective communication as being able to express oneself while $16 \%$ of male and $22 \%$ of female respondents explained it as possessing of speaking/Listening skills.

Table 3 examined the relationship between age of respondents and the importance of effective communication among couples. The younger group comprised of those respondents whose age bracket falls within 18 - 35 years whereas the older group comprised of those respondents who were 36 years and above. Findings showed that more of the younger respondents $(70.1 \%)$ had the knowledge that effective communication can improve marital relationship than the older respondents (29.9\%).

Table 2.

Sex of respondents and awareness of communication strategies.

\begin{tabular}{cccc}
\hline \multicolumn{3}{c}{ Response } \\
\hline Sex & Yes & No & Total \\
\hline Male & $92(46.7 \%)$ & $13(6.6 \%)$ & $105(53.3 \%)$ \\
Female & $62(31.5 \%)$ & $30(15.2 \%)$ & $92(46.7 \%)$ \\
Total & $154(78.2 \%)$ & $43(21.8 \%)$ & $197(100 \%)$ \\
\hline
\end{tabular}

Table 3.

Sex of respondents and meaning of effective communication.

\begin{tabular}{cccc}
\hline \multicolumn{4}{c}{ Sex } \\
\hline Response & Male & Female & Total \\
\hline Mutual understanding & $10(5.1 \%)$ & $17(8.6 \%)$ & $27(13.1 \%)$ \\
Possession of listening skills & $31(15.7 \%)$ & $45(22.8 \%)$ & $76(38.6 \%)$ \\
Ability to express oneself & $52(26.4 \%)$ & $30(15.2 \%)$ & $82(41.6 \%)$ \\
Don't know & $12(6.1 \%)$ & $0(0.0 \%)$ & $12(6.1 \%)$ \\
Total & $105(53.3 \%)$ & $92(46.7 \%)$ & $197(100.00 \%)$ \\
\hline
\end{tabular}

Table 4.

Age of respondents and importance of effective communication.

\begin{tabular}{cccc}
\hline \multicolumn{3}{c}{ Response } \\
\hline Age range & Yes & No & Total \\
\hline $18-23$ & $15(7.6 \%)$ & $3(1.5 \%)$ & $18(9.1 \%)$ \\
$24-29$ & $36(18.3 \%)$ & $18(9.1 \%)$ & $54(27.4 \%)$ \\
$30-35$ & $59(29.9 \%)$ & $7(3.6 \%)$ & $66(33.5 \%)$ \\
36 \& above & $46(23.4 \%)$ & $13(6.6 \%)$ & $59(29.9 \%)$ \\
Total & $156(79.2 \%)$ & $41(20.8 \%)$ & $197(100.00 \%)$ \\
\hline
\end{tabular}


The reason for this result may be that the younger respondents fall within the higher educational qualification groups and should be eager to learn about new information more than the older respondents. This group could be more knowledgeable about the importance of effective communication among couples because of their inquisitiveness to utilize information which has been shown to depend on the needs, skills and attitudes of individuals.

The Table 5 below examined the relationship between the age of respondents and the perceived influence of culture on effective communication strategies among couples. An important finding from this study is that most of the male respondents (41\%) agreed that culture has an influence on couple's effective communication as against their female counter parts (11.2\%). This shows that male respondents are more knowledgeable about the influence of culture on effective communication than the female respondents.

The study showed that most respondents $(36.5 \%)$ within the high educational level bracket agreed that education can affect the effectiveness of communication pattern among couples.

\section{Perception Measures}

Results from the study showed that majority of the respondents $(78.2 \%)$ were aware of the effective communication strategies among couples in Nsukka town of Enugu state and only $21.8 \%$ the respondents said that they were not aware of effective communication strategies. About $47 \%$ of the male respondents were aware of the communication strategies among couples as against their female counter parts (31.5\%).

The study findings also indicated that greater proportion of the respondents $(41.6 \%)$ were able to explain effective communication as being able to express oneself while $38.6 \%$ of them understood the "phrase" as possessing of speaking/listening skills. $13.7 \%$ of the respondents understood effective communication as couple's mutual understanding and only $6.1 \%$ said that they have no idea of what the effective communication means. The results, however, showed that $26 \%$ of male and $15 \%$ of female respondents were able to explain effective communication as being able to express oneself while $16 \%$ of male and $22 \%$ of female respondents explained it as possessing of speaking/Listening skills. The responses above showed that most of the respondents had a considerable knowledge of effective communication. This knowledge can lead the couples to develop a better understanding of each other's side of life.

When asked whether effective communication can improve marital relationship the observation in the Table 6 below showed that the greatest percentage of the sample population $(79.2 \%)$ was of the opinion that effective communication can improve marital relationship. Findings showed that more of the younger respondents $(70.1 \%)$ had the knowledge that effective

Table 5.

Sex of respondents and influence of culture on effective communication.

\begin{tabular}{cccc}
\hline \multicolumn{5}{c}{ Sex } \\
\hline Cultural influence & Male & Female & Total \\
\hline Yes & $81(41.1 \%)$ & $23(11.2 \%)$ & $104(52.3 \%)$ \\
No & $24(12.4 \%)$ & $69(35.5 \%)$ & $93(47.7 \%)$ \\
Total & $105(53.3 \%)$ & $92(46.7 \%)$ & $197(100.00 \%)$ \\
\hline
\end{tabular}

communication can improve marital relationship than the older respondents $(29.9 \%)$. Bruce (2000) corroborated this view and indicated that effective communication is the glue that holds the relationship among married couples together. The author maintained that developing effective communication strategy that will improve relationship among married couples should be a priority for every one.

The study also found that majority of the respondents $(54.2 \%)$ believed that place of residence had no influence on couple's communication strategies. The reason residence should not have influence on couples' communication strategies could be cultural. This is because the patterns of attitude and behavior set by different cultures may vary greatly. When the influence of culture on effective communication among couples was sought, the findings showed that above $50 \%$ of the respondents agreed that culture has an influence on couples' effective communication while about $47 \%$ of the respondents were of the opinion that culture has no influence on effective communication among couples. $41 \%$ of the male respondents agreed that culture has an influence on couples effective communication as against their female counter parts $(11.2 \%)$.

The results showed that almost two-third of the sample population were of the opinion that education can affect the effectiveness of communication pattern among couples. Education is a powerful instrument of change. It provides opportunities for couples to improve on their marital relationship and have the chances of staying together for longer period. Educated couples are more likely to use effective communication strategies than couples who are not educated $(P \leq .001)$. The study showed that most respondents $(36.5 \%)$ within the high educational level bracket agreed that education can affect the effectiveness of communication pattern among couples.

Finally, the study revealed that $20.5 \%$ and $30.6 \%$ of the respondents were able to identify that finding time to talk and making clear statements can minimize misunderstanding respectively in marriage relationship. This has shown that the couples' perception on communication strategies in Nsukka town is not yet "uhuru" or a success story, because much is still desired to be done. This is evidenced in the Table 6 above which indicated that almost half of the respondents could not identify the styles or steps couples can take to reduce the conflict or misunderstanding among couples.

\section{Discussion}

The central issue of this research was to examine the societal perception of communication strategies among couples in Nsukka Town. From the findings, we found out that majority of the respondents in this study had a considerable knowledge of communication strategies among married couples. For instance,

Table 6.

Level of education and perception of communication pattern by couples.

\begin{tabular}{cccc}
\hline \multicolumn{4}{c}{ Educational influence } \\
\hline Level of education & Influence comm. & Do not influence & Total \\
\hline Low education & $7(3.6 \%)$ & $13(6.6 \%)$ & $20(10.1 \%)$ \\
Medium education & $63(32 \%)$ & $36(18.3 \%)$ & $99(50.3 \%)$ \\
High education & $72(36.5 \%)$ & $6(3 \%)$ & $78(39.6 \%)$ \\
Total & $142(72.1 \%)$ & $55(27.9 \%)$ & $197(100.00 \%)$ \\
\hline
\end{tabular}


$41.6 \%$ and $38.6 \%$ of the respondents were able to identify the meaning of effective communication in marriage relationship as ability to express oneself and possession of listening/speaking skills respectively. Therefore, it does appear that many of these married couples have learnt that marriage can stand or fall on the basis of how well the couple can communicate with each other. Despite the difficulties that couples experience, those who can communicate clearly with each other have a much better chance of overcoming problems and staying together. In Nigeria, many marriages have failed because of lack of knowledge on communication strategies. Couple may have every thing going for them but they are likely to fail because of poor communication which causes conflict, misunderstanding, hurt and resentment among couples.

The high percentage response on the awareness of effective communication strategies among couples means that couples are conscious of their non-verbal and verbal communication patterns and this should be a sure road to successful relationship between them. Then, one can conclude that the awareness of communication strategies by the couples could be attributed to the fact that the study area was located right inside the university town of Nsukka where most of the respondents reside in urban and are literate who are exposed to communication styles through the media, radio or television.

The study also noted that education is paramount in communication strategies among married couples in Nigeria. This is because it affects the effectiveness of communication pattern in marriage relationship. However, majority of the respondents were of the view that education is a key to effective communication. The study indicated that educated couples communicate more effectively than the uneducated couples. This shows that education plays a pivotal role in improving marital relationship. From the analysis of data, it can be noted that education is a viable instrument in bringing about positive changes in the pattern of life of married couples.

Another major finding in this study is the issue of financial influence on effective communication among couples. In further analysis of data, it was observed that majority of the respondents did not support the idea that financial influence can affect effective communication among couples in Nsukka town of Enugu State. In support of this response, a research work carried out by Tess Thompson in 2009 showed that couples may have all the money they need, lovely children, beautiful homes, successful careers, supportive families - every thing that they need and because of poor communication skills, their marriage is failing. This simply means that whether one is rich or poor, the ability to communicate with each other is the best option among others. Both the rich and poor couples need to communicate clearly with each other so as to have a better chance of overcoming family problems. Therefore, mastering communication skills or strategies is not meant for a particular group of people, it is for every couple who wants a healthy and a successful marriage life.

The study also showed that culture has an influence on effective communication among couples in Nsukka Town. The issue of culture and its effects on communication among couples especially in a traditional setting like Nsukka cannot be overemphasized. Culture is a significant factor in determining how modes of expression are developed and used in both form and meaning. For instance, eye contact initiated by a married woman in Nsukka area has a high cultural connotation. In many communities around Nsukka Town, such women are regarded as loose, wayward and promiscuous person. In this case, there is probably no aspect of expression that does not have its cultural determinants and because the patterns of attitude and behaviors set by different cultures may vary greatly, they frequently constitute significant barriers to valid communication (Naomi, 1998). For example, passivity of married women in Nsukka area is regarded as a mark of respect to the husband. Women learn this, during socialization processes-parents make comments about marriage institution and particularly comments regarding communication between husbands and wives where they tutor their young girls not to challenge or argue with their husbands and not to talk whenever the man is talking. The reason is that the man or husband is the head and provides for the family. Children take the opinion of these figures of authority in their lives as doctrine. They always accept them as the whole truth and nothing but the truth. Later in their marriage life, these comments tend to favor some of them and to others, the comments have wizardry effects on them and as such could cause misunderstanding in the marriage relationship, because they want to adhere strictly to what they learnt from parents.

Nevertheless, this passivity of women can pose a serious problem especially when the couples are from different cultural background. Therefore, passivity of women in couples' communication is not as a result of timidity or lack of awareness but could be a people's culture which at-times may require knowledgeable interpretation. Studies have shown that many people are shocked to realize how their marriages resemble the marriages of their parents. It is very true that people learn how to be husbands and wives by watching the way their parents treat each other. This then becomes part of subconscious approach to partners when they are adults - even when they don't believe in it intellectually (Tess, 2009).

Finally, the results from the study showed that almost half of the married couples were unable to identify the steps couples take to reduce misunderstanding in marriage relationship. There are some mistakes couples make in their marriage life and to redress this, they need to know certain communication styles that can minimize misunderstanding or problems which cause difficulties in relationships. Couples who have poor communication skills often get stuck at a certain level in their career. Therefore, it is important for couples to try to understand each other's communication styles and respond accordingly. In support of this assertion, Eboni and Deborah, (2010) argued that to accomplish this, couple should realize that there are no secrets to communication, but one can get better with practice, practice, practice.

\section{Conclusion}

This research attempted to ascertain the societal perception of communication strategies among married couples in Nsukka town. Findings from the present study suggest that whereas married couples in Nsukka town know that effective communication can improve marital relationship, many of them failed to identify the steps couples take to reduce the problems of marriage relationships. This does not augur well for the country as a whole and married couples in particular. This is because without the knowledge of certain communication styles, there will be no successful marriage. Couples are therefore, encouraged to master these communication strategies so as to avoid conflict, misunderstanding, hurt and resentment in marriage life. 


\section{IYIANI, C. NGWU}

\section{REFERENCES}

Bruce, W. (2000). The biblical portrait of marriage. New York: Waterbrook, Multnomah publishing group.

Deborah, T. (1985). Why can't he hear what I'm saying? New York: Macmillan Company.

Eboni, B., \& Deborah, H. (2010). Improving couples' communication. Gainesville: University of Florida.

Emenike, O. (1997). Communication and management of organizational behavior. In A. Ndu, L. Ocho, \& B. Okeke (Eds.), Dynamics of educational Administration and management (pp. 99-108). Awka: Meks publisher Ltd.

Gottman, J., \& Levenson, R. (1988). Social psychophysiology of marriage. Google Books Com.

Harold, J. (2001). 52 Guidelines for making marriage work. Camp Hill, PA: Christian Publication.
Joyce Brothers (1982). Men and women: The difference, from what every woman should know about men as excerpted. Woman's Day, 140.

Mbazu, I. (2009). Communication as an instrument for effective instructional supervision. Nigerian Journal of Humanities and Soc. SCS, 3, Centre for academic research, U.N.N.

Naomi, T. (1998). Working with people: The helping process (2nd ed.). New York: Lippincott Coy.

Perkins, P. S. (2008). The art and science of communication. Tools for effective communication in the work place new BKT.

Robin Fields (2001). Unwed partners up to $72 \%$ in US. Los Angeles Times, 13.

Tess, T. (2009). Ten steps to better communication. Google books Com. 